\title{
Current status of violence, suicide, alcohol use, and stigma in Mexico
}

\author{
Guilherme Borges
}

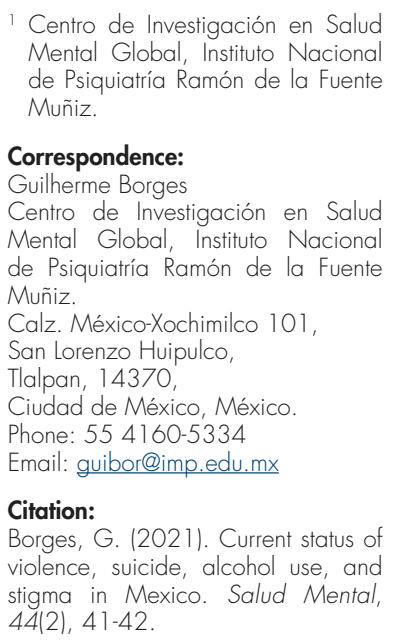

Correspondence:

Guilherme Borges

Centro de Investigación en Salud Mental Global, Instituto Nacional de Psiquiatría Ramón de la Fuente Muñiz.

Calz. México-Xochimilco 101,

San Lorenzo Huipulco,

Tlalpan, 14370

Ciudad de México, México.

Phone: 55 4160-5334

Email: guibor@imp.edu.mx

Citation:

Borges, G. (2021). Current status of violence, suicide, alcohol use, and stigma in Mexico. Salud Mental, 44(2), $41-42$

DOI: $10.17711 /$ SM.0185-3325.2021.007
Studies on the Global Burden of Disease (GBD) and its risk factors have shown worldwide the preponderant role of accidents and violence in the burden of disease and the role of alcohol consumption as a main risk factor in the current epidemiological profile (GBD 2019 Risk Factors Collaborators, 2020; GBD 2019 Diseases and Injuries Collaborators, 2020). GBD studies in Mexico have not only confirmed this (Gómez-Dantés et al., 2016), but also shown the enormous human loss entailed by violence in Mexico and the preponderant role of alcohol consumption as a risk factor. To complicate things further, whereas the suicide mortality rate fell by $32.7 \%$ between 1990 and 2016 worldwide, Mexico is experiencing a constant increase in this cause of mortality (Naghavi et al., 2019). One step to enhance coping with this complicated panorama is to give mental and neurological disorders, substance use, and suicide the role that corresponds to them, programmatically and financially, due to their implication in the burden of disease in Mexico (PAHO, 2018). This number of Salud Mental touches several of these important issues and paves the way to advance our comprehension of violence, suicide, alcohol use, and stigma in Mexico.

A recurring problem in trying to reduce the health care gap for mental health problems in the Mexican population concerns the presence of the stigma associated with mental disorders (Andrade et al., 2014). Not only does stigma prevent people from seeking specialized care, but it is an ever-present factor in people dropping out of treatments. Studying the occurrence of stigma and how to fight it is, therefore, a topical and essential issue for improving mental health care. The article by Jazmín Mora-Ríos and Miriam Ortega-Ortega is a breakthrough step in that it adapts a scale that goes beyond the mere enumeration of stigma and to encompasses idiosyncratic aspects that lie at the heart of this phenomenon, making it possible to undertake first-line cross-cultural research on this issue and the topic of discrimination at the root of stigma.

According to the Instituto Nacional de Estadística y Geografía [INEGI, National Institutte of Statistics and Geography], in 2020, 25.7 million people (21.5\% of the Mexican population) themselves-identified, as indigenous (IWGIA, 2020). The fact that we know so little about the mental health of this population in Mexico, particularly the impact of the consumption of alcoholic beverages and the violence this consumption produces towards indigenous women and children, imposes a major constraint on our current knowledge. The article by Leticia Vega and collaborators focusses on fundamental issues for mental health today: the problem of the impact on other people (wives and children) of alcohol use by the heads of households, usually males (Laslett et al., 2020) and the preponderant role of family violence in the establishment and maintenance of subjugated family relationships and the need to empower women to enable them to break free of these relationships.

The symptoms of premenstrual syndrome and the most severe premenstrual dysphoric disorder can produce discomfort in the best of cases, and even severe disability and other mental disorders such as suicidal behavior in the most severe cases (Alvarado-Esquivel, 2018). However, little is known about this in the Mexican population. The work of Meza-Moreno et al. on this issue not only draws attention to the importance of studying the phenomenon in the national context, but also provides a first approach with useful performance measurements and their association with these phenomena. In addition, it is an example of the difficulties 
inherent in studying a condition for which there is so little information and a great deal of misinformation.

Due to the COVID-19 epidemic, a large amount of attention has recently been paid to the enormous risks to which medical personnel (among other members of the health sector) are exposed in Mexico because of the risk of contagion coupled with burnout and the consequences on their mental health. Interest in the mental health of doctors and particularly of medical residents, often with long working hours, little control over their jobs, and low pay, has been rising in the country for several years now. This systematic review of the prevalence of burnout in university students, and its concomitant discussion of the measurement and instruments used to approach this phenomenon is therefore extremely timely. It is striking that the authors have not included any studies on Mexico, probably due to their inclusion criteria, although there are some initial studies in the country that could be considered in a subsequent review (Miranda-Ackerman et al., 2019; Jiménez-Ortiz et al., 2019; Asencio-López et al., 2016).

Non-suicidal self-injury (NSSI) often goes unnoticed by parents, friends, and health personnel, despite being a frequent problem in the general population of Mexico. In a random sample of the adolescent population of the Mexico City Metropolitan Zone (Benjet et al., 2017), 18.56\% of the population reported lifetime NSSI and $3.19 \%$ in the past 12 months. Among the general university population, prevalence is $13.3 \%$ and $5.3 \%$, respectively (Benjet et al., 2019). Although NSSI is frequent, there are very few studies in Mexico providing a detailed analysis of the demographic and mental health characteristics of these patients. The article by Marín-Tejeda, Martínez-Martínez, \& Santillán Torres-Torija appearing in this issue of Salud Mental is therefore an important contribution that also explores a high-risk population for NSSI, in which $35.6 \%$ reported a significant, recent pattern of self-injury. The authors also add an extremely comprehensive battery of psychopathology that undoubtedly provides a better characterization of these subjects and will also be of interest to authorities and researchers specializing in these topics.

Mexico is in an extremely delicate situation in terms of suicide mortality. Whereas the suicide mortality rate fell by $32.7 \%$ between 1990 and 2016 worldwide, Mexico is experiencing a constant increase in this cause of mortality (Naghavi et al., 2019). For decades, there has been a very unequal distribution of this rate, with high suicide rates in the north and southeast of the country (Borges, García Pacheco, \& Borsani, 2016). However, little is known about the situation in the remaining states, especially those that have seen upward trends in this cause of mortality. The article by Montserrat Fernández-López et al. is therefore particularly welcome in this issue of Salud Mental. Not only does it provide a detailed analysis of the state of Chihuahua, but it also makes important contributions to understanding the role of climate and seasonality in this suicide trend, which has received scant attention in Mexico.

\section{REFERENCES}

Alvarado-Esquivel, C. (2018). Association Between Suicidal Behavior and Clinical Features of Premenstrual Syndrome and Menstrual History: A Cross Sectional Study. Journal of Clinical Medicine Research, 10(11), 830-837. doi: 10.14740/ jocmr3571w

Andrade, L. H., Alonso, J., Mneimneh, Z., Wells, J. E., Al-Hamzawi, A., Borges, G., ... Kessler, R. C. (2014). Barriers to mental health treatment: results from the WHO World Mental Health surveys. Psychological Medicine, 44(6), 13031317. doi: 10.1017/S0033291713001943

Asencio-López, L., Almaraz-Celis, G. D., Carrillo Maciel, V., Huerta Valenzuela, P., Silva Goytia, L., Muñoz Torres, M., ... Flores Lepe, R. (2016). Burnout syndrome in first to sixth-year medical students at a private university in the north of Mexico: descriptive cross-sectional study. Medwave, 16(03). doi: 10.5867/medwave.2016.03.6432

Benjet, C., González-Herrera, I., Castro-Silva, E., Méndez, E., Borges, G., Casanova, L., \& Medina-Mora, M. E. (2017). Non-suicidal self-injury in Mexican young adults: Prevalence, associations with suicidal behavior and psychiatric disorders, and DSM-5 proposed diagnostic criteria. Journal of Affective Disorders, 215, 1-8. doi: 10.1016/j.jad.2017.03.025

Benjet, C., Gutiérrez-García, R. A., Abrego-Ramírez, A., Borges, G., CovarrubiasDíaz, A., Durán, M. D. S., ... Mortier, P. (2019). Psychopathology and self-harm among incoming first-year students in six Mexican universities. Salud Pública de México, 61(1), 16-26. doi: 10.21149/9158

Borges, G., García Pacheco, J. A., \& Borsani, L. (2016). Epidemiology of Suicidal Behavior in Mexico. In Pan American Health Organization [PAHO] (Eds.). Prevention of suicidal behavior. Washington, DC: PAHO. pp. 48-56. ISBN: 978-92-75-11919-8

GBD 2019 Diseases and Injuries Collaborators. (2020). Global burden of 369 diseases and injuries in 204 countries and territories, 1990-2019: a systematic analysis for the Global Burden of Disease Study 2019. The Lancet, 396(10258), 1204-1222. doi: 10.1016/S0140-6736(20)30925-9

GBD 2019 Risk Factors Collaborators. (2020). Global burden of 87 risk factors in 204 countries and territories, 1990-2019: a systematic analysis for the Global Burden of Disease Study 2019. The Lancet, 396(10258), 1223-1249. doi: 10.1016/S0140-6736(20)30752-2

Gómez-Dantés, H., Fullman, N., Lamadrid-Figueroa, H., Cahuana-Hurtado, L., Darney, B., Avila-Burgos, L., ... Lozano, R. (2016). Dissonant health transition in the states of Mexico, 1990-2013: a systematic analysis for the Global Burden of Disease Study 2013. The Lancet, 388(10058), 2386-2402. doi: 10.1016/S0140-6736(16)31773-1

Grupo Internacional de Trabajo sobre Asuntos Indígenas [IWGIA]. (2020). El Mundo Indigena 2020: México. Retrieved from https://www.iwgia.org/es/mexico/3745mi-2020-mexico.html

Jiménez-Ortiz, J. L., Islas-Valle, R. M., Jiménez-Ortiz, J. D., Pérez-Lizárraga, E., Hernández-García, M. E., \& González-Salazar, F. (2019). Emotional exhaustion, burnout, and perceived stress in dental students. Journal of International Medical Research, 47(9), 4251-4259. doi: 10.1177/0300060519859145

Laslett, A. M., Stanesby, O., Graham, K., Callinan, S., Karriker-Jaffe, K. J., Wilsnack, S., ... Room, R. (2020). Children's experience of physical harms and exposure to family violence from others' drinking in nine societies. Addiction Research \& Theory, 28(4), 354-364. doi: 10.1080/16066359.2019.1704272

Miranda-Ackerman, R. C., Barbosa-Camacho, F. J., Sander-Möller, M. J., Buenrostro-Jiménez, A. D., Mares-País, R., Cortes-Flores, A. O., ... GonzálezOjeda, A. (2019). Burnout syndrome prevalence during internship in public and private hospitals: a survey study in Mexico. Medical Education Online, 24(1), 1593785. doi: 10.1080/10872981.2019.1593785

Naghavi, M. (2019). Global, regional, and national burden of suicide mortality 1990 to 2016: systematic analysis for the Global Burden of Disease Study 2016. BMJ, 364, 194. doi: 10.1136/bmj.194

Organización Panamericana de la Salud [OPS]. (2018). La carga de los trastornos mentales en la Región de las Américas, 2018. Washington, DC: OPS. 